\title{
Chapter 9 \\ Migration Motives, Timing, and Outcomes of Internationally Mobile Couples
}

\author{
Marcel Erlinghagen
}

\subsection{Introduction}

The migration of couples should be understood as a product of bilateral negotiations between two partners rather than independent decisions of socially unbounded, isolated actors (Abraham and Nisic 2012; Coulter et al. 2012). However, it is very likely that the results of such negotiation processes are not gender-neutral. According to the traditional male breadwinner model, couples' migration decisions should be particularly affected by men's career prospects and women are take the role of the "trailing wife" who follows her husband(e.g. Bielby and Bielby 1992; Boyle et al. 2001; Clerge et al. 2017). Even if there is ample evidence for the trailing wife phenomenon with regard to internal residential moves, little is known about whether and how these gender-linked patterns also occur in international migration. Based on data from the first wave of the German Emigration and Remigration Panel Study (GERPS), the current chapter presents an exploration of data addressing these questions, examining findings regarding gender-linked differences in migration motives, in migration patterns, and in migration outcomes of recently emigrated or remigrated couples. It partly refers to and overlaps with my previously published more detailed paper (Erlinghagen 2020).

Findings uncovered in these data will contribute to the ongoing debate about tied movers and family-related inequalities of migration. Since most research deals with internal migration, we bring new evidence to these discussions by investigating international migration. The data discussed in this chapter also help to broaden our understanding of gender-linked factors in migration because much of the previous work on international family migration has come from less egalitarian and less economically developed countries, whereas the data in this study come from Germany,

M. Erlinghagen $(\bowtie)$

Institute of Sociology, University of Duisburg-Essen, Duisburg, Germany

e-mail: marcel.erlinghagen@uni-due.de 
where by global standards both gender equality and living standards are comparatively high.

\subsection{Theoretical Background}

In the context of migration research, there is a long tradition of relying on arguments from human capital theory (Becker 1964; Mincer 1962) and conceptualising migration as a joint household decision (Mincer 1978; Sandell 1977). These arguments have been extended by arguments from bargaining theory, claiming that the partner with the greatest bargaining power is predicted to prevail such that the weaker partner (who has less bargaining power) follows the migration preferences of his or her spouse (Abraham et al. 2010; Jacobsen and Levin 2000; Lundberg and Pollak 1996). Another strand of argumentation stresses the importance of gender roles for understanding the migration of couples (Bielby and Bielby 1992; Duncan and Perrucci 1976; Jürges 2006). More recently these approaches have been criticized because of their narrow focus on career opportunities as the main drivers of couples' or families' migration. It is argued that the life course perspective (cf. Elder 2003; Mayer 2009) could broaden our understanding of the complex migration decision process by taking previous experiences (e.g. former migration episodes), major life events (e.g. marriage, widowhood, birth of a child), and interrelations between different spheres of life (e.g. family, education, labour market) into account (e.g. Clark and Davies Withers 2007; Cooke 2008; Geist and McManus 2008). In the present chapter, we take these lines of thought together in a combined theoretical approach including human capital and bargaining arguments, aspects of gender roles, and a dynamic life course perspective.

\subsection{State of Research}

With regard to gender differences in the context of couples' migration there is ample empirical evidence for the trailing wife phenomenon and its complex causes and consequences (e.g. Bielby and Bielby 1992; Boyle et al. 2001; Clerge et al. 2017). The couples' migration decisions are dominated by men's career prospects. Women typically play the part of the trailing or tied partner who either follows her husband ("tied mover") or stays with her husband ("tied stayer"; Cooke 2013). In addition to the question of who dominates couples' migration decisions, there are also many analyses that focus on the consequences of spatial mobility on men's and women's careers. Evidence has repeatedly indicated that female spouses experience earning losses as well as lower labour market prospects after moving (e.g. Boyle et al. 2001; Lersch 2016; McKinnish 2008). 
However, this research has some important limitations. First, most research on the migration of couples has been restricted to internal residential mobility. In the case of quantitative research, this is mainly because representative large data sets are only available on a national scale. Information about the process of international migration (e.g. family information before and after border crossing) is lacking (e.g. Vermeulen 2010). National surveys and panels usually only reflect migration processes within national borders. As a result, it is unknown whether the observed pattern of internal mobility generalises to international migration of couples. Second, compared to the manifold research on objective outcome differences of migration for male or female spouses, there is to the best of our knowledge no quantitative comparable research that addresses possible gender differences regarding the consequences of couples' migration in terms of subjective well-being. Third-as discussed by Amcoff and Niedomysl (2015)—quantitative as well as qualitative research on migration of couples generally neglects the phenomenon of remigration, which may have different motives and possibly causes different consequences for families and couples compared to emigration. Third, the results of existing qualitative research on international migration of couples support the trailing-wifehypothesis. However, this research relies mostly on interviews of small numbers of migrants (e.g. King-O'Riain 2015) and/or of very specific groups of migrants (e.g. highly skilled expatriates; Cangia et al. 2018). In addition, such research is mainly restricted to migration from particular regions or countries of origin to particular regions or countries of destination (e.g. Willis and Yeoh 2010; Schmalzbauer 2009; Kõu et al. 2015; Mayes and Koshy 2017). Thus, even for specific subgroups of migrants it remains unclear whether and to what extent such findings can be generalised.

\subsection{Data and Methods}

\subsubsection{Data}

Data from the first wave of the German Emigration and Remigration Panel Study (GERPS) (Ette et al. 2021) are examined in the following analyses. We are interested in recently migrated individuals, so all respondents who reported emigrating or remigrating prior to 2017 were excluded from further analyses. In addition, we excluded any participants whose interviews were incomplete. Under these conditions data from 3647 emigrants and 6150 remigrants were retained for further analyses.

In GERPS all respondents were asked questions about their romantic relationship or partnership status 3 months before they moved and whether this relationship has continued after migration. Although we concentrated exclusively on recently migrated individuals, several months to 2 years could have elapsed between the 
event of migration and the time of the interview. In GERPS (wave 1) the minimum time elapsed between the reported event of migration and the interview date was 0 months and the maximum was 25 months (mean: 11.7 months; median: 12.0 months). Those respondents who reported a partnership at the time of migration were also asked if this relationship was intact at the time of the interview. The following analyses only include migrants who reported a stable and continuing partnership throughout the whole migration process ( 3 months before migration up to the interview in wave 1; for migration related separations see Baykara-Krumme et al. 2021). In addition, we deleted cases with no valid gender information and also individuals who reported a same-sex marriage. Under these conditions, data from 2257 emigrants and 3191 remigrants remained in our data set.

\subsubsection{Dependent Variables}

A variety of dependent variables are examined in order to address the various research questions we want to answer in this chapter. Below, we describe how these dependent variables are derived from GERPS data. Next, we discuss the selection of different regression techniques suited to each type of variable and analysis conducted. Finally, the regression results are presented and interpreted.

\subsubsection{Migration Motives}

The GERPS participants were asked about the importance of several possible migration motives for their own migration decision, and responses were given using a seven-point Likert scale ranging from (1) "not important at all" to (7) "very important". In the following sections, we concentrate on three motives, "career of the partner", "own career prospects", and "family reasons", because we can assume these domains of motives in particular are strongly connected to gender role beliefs and attitudes.

\subsubsection{Migration Pattern}

We considered whether a spouse is trailing or leading the migration process in two different ways: First, we looked at which partner (male or female) was the driving force behind the couple's migration decision. Second, we examined the timing of individual migration. For our analyses we distinguish not just trailing and nontrailing spouses, but three groups: (1) trailing spouses, (2) leading spouses, and (3) egalitarian spouses.

We gained insight into the driving force behind each couple's migration decision through answers to the following GERPS question: "If you remember your migration decision: Who has been the driving force? You or your partner?" The 
participants were given the following response categories: (1) "my partner", (2) "I myself", (3) "Both in equal shares", and (4) "don't know". We identify a participant as a "trailing spouse" if he or she chooses category (1). If he or she chooses category (2), we identify the person as a "leading spouse". If participants select category (3) or (4), we define them as "egalitarian spouses".

To learn more about the timing of migration, we rely on the following GERPS question: "What was the timing of your migration like: Which of you migrated first or did you migrate together?" The participants could choose among the following categories: (1) "My partner already lived there at the time we met", (2) "My partner migrated first", (3) "My partner migrated after me", (4) "We migrated at the same time", (5) "My partner is still living in Germany" [emigrants only] / "...in the country I have lived before" [remigrants only], and (6) "My partner lives in another country". We define a participant as a "trailing spouse" if he or she chooses category (1) or (2). If he or she chooses category (3), (5), or (6) we consider the participant to be a "leading spouse". Participants who selected category (4) were defined as "egalitarian spouses".

\subsubsection{Migration Outcomes}

Based on previous research (e.g. Boyle et al. 2001; Lersch 2016; McKinnish 2008), we also expected gender differences in migration outcomes for male and female spouses. There are several areas of life to consider when looking at possible outcome differences. We will concentrate on one objective and two subjective measures. These measures are (1) objective changes in individual employment status comparing status 3 month prior to migration to the time of the interview, (2) subjective assessment of social isolation at the time of the interview as measured by an additive isolation index with values from 3 (very low feeling of isolation) to 15 (very high feeling of isolation), and finally (3) the subjective rating of overall life satisfaction (11-point scale). We made separate estimations for trailing partners, partners from egalitarian couples, and leading partners.

\subsubsection{Explaining and Control Variables}

Gender is the central explaining variable in all our models since we are interested in possible differences between male and female partners in migration motives, migration patterns, and migration outcomes. Later, we control for age and include information about individual migration experiences. Although GERPS is restricted to German citizens it is possible that some participants had previous experience with migration as they may have migrated from abroad to Germany ("first generation migrant") or at least one of their parents may have moved to Germany before the participant was born ("second generation migrant"). In our analyses of migration 
motives and migration pattern, we also ask whether children were part of emigrant's or remigrant's household 3 month before migration. In contrast, the estimations regarding migration outcomes take into account whether children were part of emigrant's or remigrant's household at the time of the (post-migration) interview. In both cases, we distinguish among households with at least one child below the age of 7 years, households with children between 7 and 16 years of age, and households with no children below the age of 17 years. In addition, we include a control that indicates whether the partner currently lives in the same household like the interviewed migrant or if the two partners are currently living at different locations. The estimations regarding life satisfaction and social isolation as an outcome of migration both control for migration motives and for participants' current main activity status (employed, self-employed, not employed, in education and training, and other activities). The estimations on migration motives and patterns control for the main activity status 3 month before migration. We further control for current educational status measured by the highest occupational degree ("no degree", "completed vocational training", and "college or university degree"). We also include proxyinformation about the relative educational status of the not-interviewed partner and differentiate the three categories "partner has a lower degree", "partner has an equal degree", and "partner has a higher degree". To reflect differences in personality traits we include a self-reported measure of risk attitudes. Each respondent was asked to indicate on an 11-point scale (ranging from $0=$ "not at all willing to take risks" to $10=$ "very willing to take risks") if he or she is someone who is willing to take risks (see Lübke et al. 2021 for analyses on emigrants' and remigrants' risk tolerance).

\subsection{Results}

\subsubsection{Migration Motives}

Table 9.1 shows the results of Generalised Ordered Logit Regressions (GOLRs; Williams 2018) on gender effects and differences between emigrants and remigrants regarding different migration motives controlling for other relevant independent variables. In addition, we include an interaction effect for female remigrants. Including this interaction effect enables us to investigate whether there is an additional effect for female remigrants on the self-perceived importance of selected migration motives beside a basic gender effect and a basic effect of remigration. In general, GOLR accounts for the ordinal scale of our dependent variable but can relax the parallel odds assumption (Williams 2016). Instead of one coefficient as in standard ordinal regression estimations, GOLR provides single coefficients (here: 6) each estimating the effect of the independent variable of interest (here: gender and emigration or remigration) on a further one-point increase in the dependent ordinal variable (here: importance of selected migration motives on a 7-point scale). 


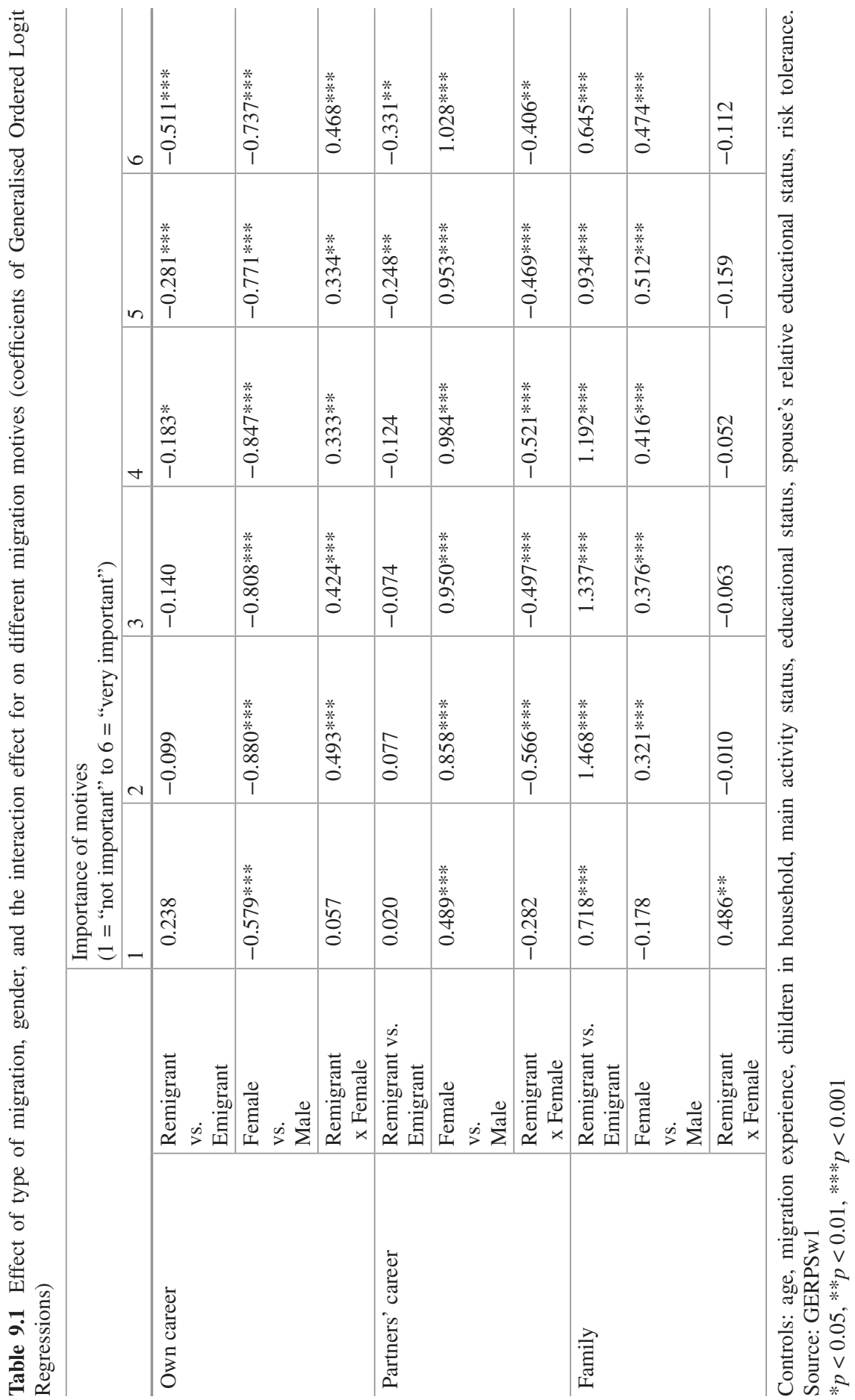


Table 9.1 shows that emigrants reported significantly higher importance for career-related migration motives than remigrants reported. In contrast, familyrelated migration motives were more relevant for remigrants than for emigrants. In addition, there were clear basic gender differences in migration motives that follow the traditional gender role model of the male breadwinner. For female participants, own career prospects were significantly less important as migration motives than for male participants. In contrast, the spouse's career and family-related reasons had significantly greater importance as migration motives for female migrants compared to males. The coefficients of the interaction term for female remigrants showed that when such basic gender and remigration effects were controlled for, the importance of female remigrants' own career prospects significantly increased and the importance of their partner's career prospects significantly decreased."These results mean that although migrating females generally followed the same traditionally gendered motive pattern, the male breadwinner model decreased in relevance for remigrating female spouses compared to emigrating females.

\subsubsection{Migration Pattern}

Our next questions were whether and how gender affects individual propensity to become a trailing or leading spouse during emigration and remigration (see also Erlinghagen 2020). For this purpose, we estimated multinomial logistic regressions (Hosmer et al. 2013, pp. 269-311). As described above, we derived two different dependent variables from GERPS. The first variable is a measure of which partner (male or female) was the driving force behind couple's migration decision. The second variable contains information about which, if either, spouse (male or female) moved first (timing). For these migration pattern analyses, the reference was "egalitarian spouse" with "trailing spouse" and "leading spouse" as the competing patterns. The results are presented as relative risk ratios (RRR). Separated models for emigrant and for remigrant participants were estimated. The results provide evidence regarding individual propensities to be a trailing spouse or a leading spouse compared to egalitarian spouses, controlling for demographic and social-structural variables as well as for individual differences in migration motives and personality traits.

Table 9.2 provides RRRs of female emigrants and remigrants compared to males with respect to (a) the migration decision and (b) the timing of migration. For remigration decisions, we found a gender effect in only one specific situation: Remigrating women in stable partnerships had a significantly higher propensity to become a leading spouse compared to men. In other words, women were more likely than men to be the leading force in the decision making of couples who remigrated. Looking at the timing of remigration we find a similar pattern: Women were more likely than men to move first and to be followed by their trailing husbands. However, the results for the timing of emigration were completely different. When couples emigrated, women were indeed the trailing partners $(R R R=1.702)$ and 
Table 9.2 Relative Risk Ratios (RRR) of female emigrants and remigrants compared to men to be a trailing or leading spouse regarding (a) migration decision (ref.: egalitarian decision) and (b) timing of migration (ref.: migration at the same point in time)

\begin{tabular}{|c|c|c|c|c|}
\hline & \multicolumn{4}{|c|}{ (a) Migration decision } \\
\hline & \multicolumn{2}{|c|}{ Emigrants } & \multicolumn{2}{|l|}{ Remigrants } \\
\hline & trailing spouse & leading spouse & trailing spouse & leading spouse \\
\hline & RRR & RRR & RRR & RRR \\
\hline Male & ref. & ref. & ref. & ref. \\
\hline Female & 1.011 & 0.818 & 0.904 & $1.416^{* * * *}$ \\
\hline $\mathrm{R}^{2}$ & \multicolumn{2}{|l|}{0.200} & \multicolumn{2}{|l|}{0.120} \\
\hline LR $\mathrm{chi}^{2}$ & \multicolumn{2}{|l|}{925.48} & \multicolumn{2}{|l|}{751.35} \\
\hline \multirow[t]{5}{*}{$\mathrm{N}$} & \multicolumn{2}{|l|}{2208} & \multicolumn{2}{|l|}{3171} \\
\hline & \multicolumn{4}{|c|}{ (b) Timing of migration } \\
\hline & \multicolumn{2}{|c|}{ Emigrants } & \multicolumn{2}{|l|}{ Remigrants } \\
\hline & trailing spouse & leading spouse & trailing spouse & leading spouse \\
\hline & RRR & RRR & RRR & RRR \\
\hline Male & ref. & ref. & ref. & ref. \\
\hline Female & $1.702 * * *$ & $0.679 * *$ & 0.908 & $1.598 * * *$ \\
\hline $\mathrm{R}^{2}$ & \multicolumn{2}{|l|}{0.208} & \multicolumn{2}{|l|}{0.130} \\
\hline LR chi ${ }^{2}$ & \multicolumn{2}{|l|}{989.24} & \multicolumn{2}{|l|}{877.07} \\
\hline$N$ & \multicolumn{2}{|l|}{2210} & \multicolumn{2}{|l|}{3169} \\
\hline
\end{tabular}

Controls: age, age $^{2}$, migration experience, children in household, main activity status, educational status, spouse's relative educational status, risk tolerance, migration motives. Source: GERPSw1 $* p<0.05, * * p<0.01, * * * p<0.001$

they were significantly less likely to lead the emigration process $(R R R=0.679)$. However, the decision towards and the timing of remigration within couples is led by women independent of age, education, migration experience, migration motives, and personality traits.

\subsubsection{Migration Outcomes}

The result of different regression analyses on three important outcome variables are presented in Table 9.3. With regard to overall life satisfaction (11-point scale) and social isolation (13-point index), we conduct rating scale regressions with Bernoulli quasi maximum likelihood estimations (Studer and Winkelmann 2016) using the glm command in STATA as recommended in Studer and Winkelmann (2011, p. 8). The results on employment continuity $(0=$ no/ $1=$ yes $)$ relies on binary logistic regression (Hosmer et al. 2013, pp. 35-47).

With regard to employment continuity, there do not appear to be negative outcomes for male or female trailing partners compared to couples reporting egalitarian migration decisions and synchronised timing patterns of migration-and this held 
Table 9.3 Correlations between gender, the decision and timing patterns of migration, and outcome variables

\begin{tabular}{|c|c|c|c|c|c|}
\hline \multicolumn{3}{|l|}{ Decision } & \multirow{2}{*}{\begin{tabular}{|l|}
$\begin{array}{l}\text { Continues } \\
\text { employment }\end{array}$ \\
-0.524 \\
\end{tabular}} & \multirow{2}{*}{\begin{tabular}{|l|}
$\begin{array}{l}\text { Overall life } \\
\text { satisfaction }^{1}\end{array}$ \\
$-0.182 *$ \\
\end{tabular}} & \multirow{2}{*}{$\begin{array}{c}\begin{array}{l}\text { Social isolation } \\
\text { index }^{2}\end{array} \\
0.105\end{array}$} \\
\hline Emigrants & male & trailing & & & \\
\hline & & leading & $0.771^{*}$ & -0.080 & 0.021 \\
\hline & female & trailing & -0.325 & $-0.222 * * *$ & $0.145^{* *}$ \\
\hline & & leading & $0.934 * * *$ & -0.090 & 0.009 \\
\hline \multirow[t]{4}{*}{ Remigrants } & male & trailing & -0.298 & -0.077 & 0.062 \\
\hline & & leading & 0.172 & -0.086 & $0.068 *$ \\
\hline & female & trailing & -0.307 & $-0.353 * * *$ & $0.098^{*}$ \\
\hline & & leading & -0.017 & -0.024 & 0.063 \\
\hline \multicolumn{3}{|l|}{ Timing } & \begin{tabular}{|l|}
$\begin{array}{l}\text { Continues } \\
\text { employment }\end{array}$ \\
\end{tabular} & $\begin{array}{l}\text { Overall life } \\
\text { satisfaction }\end{array}$ & $\begin{array}{l}\text { Social isolation } \\
\text { index }^{2}\end{array}$ \\
\hline \multirow[t]{4}{*}{ Emigrants } & \multirow[t]{2}{*}{ male } & trailing & -0.026 & -0.119 & 0.067 \\
\hline & & leading & $1.055^{* *}$ & -0.068 & 0.028 \\
\hline & \multirow[t]{2}{*}{ female } & trailing & $0.482 *$ & -0.089 & 0.021 \\
\hline & & leading & $1.290 * *$ & -0.063 & -0.085 \\
\hline \multirow[t]{4}{*}{ Remigrants } & \multirow[t]{2}{*}{ male } & trailing & 0.363 & -0.027 & -0.016 \\
\hline & & leading & 0.094 & $-0.170 * *$ & $0.143^{* *}$ \\
\hline & \multirow[t]{2}{*}{ female } & trailing & 0.297 & 0.034 & -0.024 \\
\hline & & leading & -0.276 & 0.009 & 0.027 \\
\hline
\end{tabular}

Controls: age, migration experience, children in household, partner lives in household, educational status, spouse's relative educational status, risk tolerance. ${ }^{1,2}$ Further controls: main activity status, migration motives. Source: GERPSw1

$* p<0.05, * * p<0.01, * * * p<0.001$

true for both emigration and remigration. Instead, we found a positive correlation for leading emigrating spouses: The leading spouses who emigrated showed a higher propensity for employment continuity during the migration process than individuals in partnerships that were egalitarian with respect to migration decision and timing. This pattern is fully consistent with our results on migration motives, since career-related motives play a much greater role in understanding emigration than remigration. In light of the trailing wife hypothesis, we did not observe a negative burden of emigration or remigration on employed women with regard to employment discontinuity. However, it is quite possible that women who trail their partners when migrating face job and career challenges or setbacks in terms of working conditions, wages, or career opportunities after migration. Future analyses are needed to further investigate the possible gender-related impacts on employment penalties of migration.

In contrast, when we looked at overall life satisfaction and social isolation we found evidence of a psychological burden for women who followed their partners. These trailing women reported significantly lower overall life satisfaction and a 
significantly higher perceived social isolation in both the recently emigrated or remigrated groups. For male migrants living in stable partnerships, no such correlations were found. Instead, results suggested that leading male remigrants pay another kind of psychological toll for migration. The results indicated that not trailing but leading remigrating husbands experienced significantly lower life satisfaction and a significant higher perceived social isolation. This seems particularly true when we look at timing of migration: Men who moved before their partners reported lower life satisfaction and increased feelings of social isolation even if their partners had since also remigrated and when other important covariates were controlled for.

\subsection{Discussion}

This chapter presented analyses of data from the first wave of the German Emigration and Remigration Panel Study (GERPS) to explore the role of gender differences in migration motives, patterns, and outcomes in recently emigrated or remigrated couples. The analyses are theoretically framed by the so called trailing wife hypothesis that suggests a clear gender-related migration pattern following traditional gender roles. Based on this hypothesis, men are expected to lead the decision as well as the timing of migration and women are expected take the role of the trailing spouse who follows.

There is ample evidence that supports the trailing wife hypothesis, but only for internal residential mobility within certain countries. However, up until now there has been limited and ambiguous evidence regarding whether and how emigration of couples follows the same patterns as internal moves. In addition, almost nothing is known about the remigration of couples, although there are substantial theoretical arguments that remigration follows somewhat different patterns than emigration.

There are certain limitations to keep in mind for the research presented in this chapter as well. The study presented here is of couples but is based on a survey of individuals. Thus, all relevant information on partners' status or behaviour relies on proxy reports given by the interviewed partner. This could lead to biased results since a respondent may not know or may not want to report the actual answer to a certain question regarding his or her partner. There is an ongoing debate about the assets and drawbacks of proxy versus self-report measures (e.g. Lee and Lee 2012; Moore 1988). One disadvantage of self-report measures in household or multi-actor surveys is, however, the danger of nonresponse and possible selectivity bias (e.g. Havermans et al. 2015; Kalmijn and Liefbroer 2011; Schröder et al. 2012). Ultimately, we cannot be certain if and how our results are systematically biased by our use of proxy information. However, GERPS is unique and seems to be the only available database that enables us to conduct longitudinal analyses to investigate migration trajectories of internationally mobile couples. It has to remain an open research question if future analyses relying on (not yet existing) more sophisticated 
multi-actor surveys will lead to different, maybe less biased results. In addition, it must be clear that the results are based on data for emigration from and remigrating to Germany as one of the world's leading economies and best developed democratic welfare states. Thus, the findings cannot be generalised to migration trajectories of couples emigrating from or remigrating to poorer and much more insecure world regions of the "global south" to the highly developed economies of the "global north".

Despite such limitations, the paper provides new insights into migration trajectories of internationally mobile couples. First, the presented analyses showed that emigration and remigration motives of German couples follow clear traditional gender roles. In line with the male breadwinner model, womens' own career prospects are less important to women as a migration motive. Instead, their partner's career prospects as well as family-related reasons are more important as motives for female emigration as well as remigration.

The evidence indicated that the timing of couples' emigration followed the traditional trailing wife pattern. Specifically, women were more likely have followed their partners who had already moved abroad. Women were also less likely to take on the role of the leading spouse by emigrating in advance of their partners. However, our results also revealed different patterns among emigrating and remigrating couples. Women were more likely to remigrate, or move back to Germany, in advance of their male partners, even controlling for age, individual migration experiences, education, partner's relative education, individual risk attitudes, and migration motives. Furthermore, when looking at migration decisions, we found no significant gender effect for emigration but a greater tendency for women to be the leading force in the remigration decision making of couples.

Turning to migration outcomes, we find evidence for at least some psychological burden for women. If women are the trailing partner with respect to emigration or remigration decisions, this is obviously correlated with a decrease in overall life satisfaction as well as an increase in perceived social isolation after migration. However, under some circumstances men also suffer psychologically. Specifically, male partners who have remigrated in advance of their female partners report a lower life satisfaction and a higher perceived isolation.

We can conclude that emigration and remigration motives are strongly gendered consistent with traditional male breadwinner norms. However, actual migration decision and timing only partly follow such trajectories. With regard to emigration, we have evidence supporting the trailing wife hypothesis. But it also turns out that remigration obviously follows (at least partly) other rules. To some extent, gender norms lose their importance for couples who are returning to Germany. Focusing on possible gender effects in migration outcome, it is apparent that gender effects diminish even further. There are no effects on employment continuity of male and female migrants living in stable partnerships. However, female migrants experience some psychological burden if they are the following partner in migration decisions. To be the trailing wife seems to result in lower life satisfaction and higher perceived social isolation. In contrast, leading men seems to suffer from lower life satisfaction 
and higher perceived isolation if they have remigrated before their partners. The coincidence of suffering trailing wives and suffering leading husbands fits traditional gender role expectations in which women are expected or even forced to follow their male partners, and men are forced to temporarily leave their families because of their perceived responsibility for their families' subsistence.

Since the aim of this chapter was to provide first explorative overview of possible gender differences in migration motives, patterns, and outcomes of couples, future research should undertake analyses to look at these variables in more detail. GERPS provides a database very well suited to these purposes, particularly once further waves become available during the coming years.

\section{References}

Abraham, M., Auspurg, K., \& Hinz, T. (2010). Migration decisions within dual-earner partnerships: A test of bargaining theory. Journal of Marriage and Family, 72(4), 876-892.

Abraham, M., \& Nisic, N. (2012). A simple mobility game for couples' migration decisions and some quasi-experimental evidence. Rationality and Society, 24(2), 168-197.

Amcoff, J., \& Niedomysl, T. (2015). Is the tied returnee male or female? The trailing spouse thesis reconsidered. Population, Space and Place, 21(8), 872-881.

Baykara-Krumme, H., Erlinghagen, M., \& Mansfeld, L. (2021). Disruption of family lives in the course of migration: 'Tied Migrants' and partnership breakup patterns among German (r) emigrants. In M. Erlinghagen, A. Ette, N. F. Schneider, \& N. Witte (Eds.), The global lives of German migrants. Consequences of international migration across the life course. Cham: Springer.

Becker, G. S. (1964). Human capital: A theoretical and empirical analysis, with special reference to education. New York: Columbia University Press.

Bielby, W. T., \& Bielby, D. D. (1992). I will follow him: Family ties, gender-role beliefs, and reluctance to relocate for a better job. American Journal of Sociology, 97(5), 1241-1267.

Boyle, P., Cooke, T. J., Halfacree, K., \& Smith, D. (2001). A cross-national comparison of the impact of family migration on women's employment status. Demography, 38(2), 201-213.

Cangia, F., Levitan, D., \& Zittoun, T. (2018). Family, boundaries and transformation. The international mobility of professionals and their families. Migration Letters, 15, 1.

Clark, W. A. V., \& Davies Withers, S. (2007). Family migration and mobility sequences in the United States. Demographic Research, 17, 591-622.

Clerge, O., Sanchez-Soto, G., Song, J., \& Luke, N. (2017). 'I would really like to go where you go': Rethinking migration decision-making among educated tied movers. Population, Space and Place, 23(2), e1990.

Cooke, T. J. (2008). Migration in a family way. Population, Space and Place, 14(4), 255-265.

Cooke, T. J. (2013). All tied up: Tied staying and tied migration within the United States, 1997 to 2007. Demographic Research, 29, 817-836.

Coulter, R., Ham, M., \& Feijten, P. (2012). Partner (dis)agreement on moving desires and the subsequent moving behaviour of couples. Population, Space and Place, 18(1), 16-30.

Duncan, R. P., \& Perrucci, C. C. (1976). Dual occupation families and migration. American Sociological Review, 41(2), 252.

Elder, G. H. (2003). The life course in time and place. In W. R. Heinz \& V. W. Marshall (Eds.), Social dynamics of the life course: Transitions, institutions, and interrelations (pp. 57-71). New York: de Gruyter.

Erlinghagen, M. (2020). Love in motion: Migration patterns of internationally mobile couples. Population, Space and Place Online First. 
Ette, A., Décieux, J. P., Erlinghagen, M., Auditor, J. G., Sander, N., Schneider, N. F., \& Witte, N. (2021). Surveying across borders: The experiences of the german emigration and remigration panel study. In M. Erlinghagen, A. Ette, N. F. Schneider, \& N. Witte (Eds.), The global lives of German migrants. consequences of international migration across the life course. Cham: Springer.

Geist, C., \& McManus, P. A. (2008). Geographical mobility over the life course: Motivations and implications. Population, Space and Place, 14(4), 283-303.

Havermans, N., Vanassche, S., \& Matthijs, K. (2015). Methodological challenges of including children in family research: Measurement equivalence, selection bias and social desirability. Child Indicators Research, 8(4), 975-997.

Hosmer, D. W., Lemeshow, S., \& Sturdivant, R. X. (2013). Applied logistic regression. Hoboken: Wiley.

Jacobsen, J. P., \& Levin, L. M. (2000). The effects of internal migration on the relative economic status of women and men. The Journal of Socio-Economics, 29(3), 291-304.

Jürges, H. (2006). Gender ideology, division of housework, and the geographic mobility of families. Review of Economics of the Household, 4(4), 299-323.

Kalmijn, M., \& Liefbroer, A. C. (2011). Nonresponse of secondary respondents in multi-actor surveys: Determinants, consequences, and possible remedies. Journal of Family Issues, 32(6), 735-766.

King-O'Riain, R. C. (2015). Emotional streaming and transconnectivity: Skype and emotion practices in transnational families in Ireland. Global Networks, 15(2), 256-273.

Kõu, A., van Wissen, L., van Dijk, J., \& Bailey, A. (2015). A life course approach to high-skilled migration: Lived experiences of indians in the Netherlands. Journal of Ethnic and Migration Studies, 41(10), 1644-1663.

Lee, J., \& Lee, S. (2012). Does it matter who responded to the survey? Trends in the U.S. gender earnings gap revisited. Industrial Relations Review, 65, 148-160.

Lersch, P. M. (2016). Family migration and subsequent employment: The effect of gender ideology. Journal of Marriage and Family, 78(1), 230-245.

Lübke, C., Décieux, J. P., Erlinghagen, M., \& Wagner, G. G. (2021). Comparing the risk attitudes of internationally mobile and non-mobile Germans. In M. Erlinghagen, A. Ette, N. F. Schneider, $\& \mathrm{~N}$. Witte (Eds.), The global lives of German migrants. consequences of international migration across the life course. Cham: Springer.

Lundberg, S., \& Pollak, R. A. (1996). Bargaining and distribution in marriage. Journal of Economic Perspectives, 10(4), 139-158.

Mayer, K. U. (2009). New directions in life course research. Annual Review of Sociology, 35, 413-433.

Mayes, R., \& Koshy, P. (2017). Transnational labour migration and the place of reproductive labour: Trailing wives and community support in Boddington. Work, Employment and Society, 32(4), 670-686.

McKinnish, T. (2008). Spousal mobility and earnings. Demography, 45(4), 829-849.

Mincer, J. (1962). On-the-job training: Costs, returns, and some implications. Journal of Political Economy, 70(suppl), 50-79.

Mincer, J. (1978). Family migration decisions. Journal of Political Economy, 86(5), 749-773.

Moore, J. C. (1988). Self proxy response status and survey response quality-a review of the literature. Journal of Official Statistics, 4(2), 155-172.

Sandell, S. H. (1977). Women and the economics of family migration. The Review of Economics and Statistics, 59(4), 406-414.

Schmalzbauer, L. (2009). Gender on a new frontier: Mexican migration in the rural mountain west. Gender \& Society, 23(6), 747-767.

Schröder, J., Castiglioni, L., Brüderl, J., \& Krieger, U. (2012). The influence of relationship quality on the participation of secondary respondents: Results from the German family panel. Comparative Population Studies, 37(3-4), 591-614. 
Studer, R., and Winkelmann, R.. (2016) Econometric analysis of ratings with an application to health and wellbeing. SSRN Electronic Journal.

Studer, R., \& Winkelmann, R. (2011). Specification and estimation of rating scale models-with an application to the determinants of life satisfaction. Berlin: SOEPpapers.

Vermeulen, H. (2010). Segmented assimilation and cross-national comparative research on the integration of immigrants and their children. Ethnic and Racial Studies, 33(7), 1214-1230.

Williams, R. (2016). Understanding and interpreting generalized ordered logit models. The Journal of Mathematical Sociology, 40(1), 7-20.

Williams, R. (2018). Generalized ordered logit/partial proportional odds models for ordinal dependent variables. The Stata Journal: Promoting Communications on Statistics and Stata, $6(1), 58-82$.

Willis, K. D., \& Yeoh, B. S. A. (2010). Gender and transnational household strategies: Singaporean migration to China. Regional Studies, 34(3), 253-264.

Open Access This chapter is licensed under the terms of the Creative Commons Attribution 4.0 International License (http://creativecommons.org/licenses/by/4.0/), which permits use, sharing, adaptation, distribution and reproduction in any medium or format, as long as you give appropriate credit to the original author(s) and the source, provide a link to the Creative Commons license and indicate if changes were made.

The images or other third party material in this chapter are included in the chapter's Creative Commons license, unless indicated otherwise in a credit line to the material. If material is not included in the chapter's Creative Commons license and your intended use is not permitted by statutory regulation or exceeds the permitted use, you will need to obtain permission directly from the copyright holder.

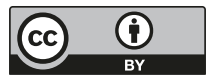

